\title{
Using an online intervention to improve menstrual health literacy and self-management in young women: a pilot study
}

Mike Armour ( $\square$ m.armour@westernsydney.edu.au )

Western Sydney University https://orcid.org/0000-0001-7539-9851

Kelly Parry

Western Sydney University

Christina Curry

Western Sydney University

Tania Ferfolja

Western Sydney University

Melissa Parker

Toobah Farooqi

Western Sydney University

Freya Macmillan

Caroline Smith

Kathryn Holmes

\section{Research Article}

Keywords: health literacy, menstruation, dysmenorrhea, education

Posted Date: August 26th, 2021

DOI: https://doi.org/10.21203/rs.3.rs-841718/v1

License: (c) (i) This work is licensed under a Creative Commons Attribution 4.0 International License. Read Full License 


\section{Abstract}

\section{Introduction}

Menstrual cycle-related conditions, such as dysmenorrhea and heavy bleeding, are common amongst those under 25. Despite having significant impact on work, education and social activities, most do not seek medical advice, preferring to self-manage their symptoms. This pilot pre- and post-test study aimed to determine if a web-based intervention could improve health literacy, reduce menstrual symptoms, and encourage health-seeking behaviour in those at risk of conditions such as endometriosis.

\section{Methods}

A steering group of menstrual health experts, young women and teachers developed a web-based resource containing two sections: information on the menstrual cycle, including conditions such as dysmenorrhea; and self-management strategies including yoga, meditation, dietary advice, heat and acupressure. Recruitment was via social media. The intervention was undertaken for three menstrual cycles. Outcomes were collected on health literacy measures, doctors' visits, symptom severity and selfcare usage.

\section{Results}

Seventy-five women with a mean age of 20.4 years enrolled in the web-based resource, and 56 (75\%) completed the intervention. Forty-three percent visited their doctor regarding their menstrual symptoms during the study period, with $84 \%$ indicating that they made the appointment due to the intervention; over half $(56 \%)$ who visited their doctor received a referral to a gynaecologist. Self-care usage increased with $60 \%$ reporting changes in the way they managed their menstrual symptoms. There were clinically relevant improvements in health literacy reflecting improved confidence of participants regarding adequate information and skills to manage their symptoms. Almost half (48.8\%) said the intervention had changed what they thought was a 'normal' period and over a third (35\%) said it corrected previous misunderstandings they had about periods and the menstrual cycle. Ninety-four percent could identify the symptoms of endometriosis after using the intervention.

\section{Conclusion}

A low-cost, web-based intervention can improve health literacy, provide effective options for selfmanagement of menstrual cycle-related conditions and motivate young women to see medical advice.

\section{Introduction}


Menstrual conditions, such as dysmenorrhea (period pain) and heavy menstrual bleeding (HMB), are common in young women worldwide [1, 2]. Dysmenorrhea is very common in young Australian women, with research showing over $90 \%$ of those under 25 reporting regular dysmenorrhea $[3,4]$. Despite the significant impact menstrual symptoms such as dysmenorrhea have on academic attendance and performance [3-5], many women, regardless of age, think that pain is a 'normal' part of being a woman [6]. Most of these women do not seek medical help but rather use self-management [7]. However, they are often unsure which self-management strategies are effective and often report only partial symptom relief $[7,8]$.

The Institute of Medicine defines health literacy as "the degree to which individuals have the capacity to obtain, process, and understand basic health-related decisions" [9]. In an educational context, the Australian Health and Physical Education (HPE) curriculum [10] focuses on developing knowledge, understanding and skills related to the three dimensions of health literacy: functional, interactive and critical dimensions, where health literacy is considered a personal and community asset to be developed, evaluated, enriched and communicated. With a specific focus on menstrual health literacy, the HPE curriculum includes sexuality and sexual and reproductive health, puberty, and access to health services. However, almost $50 \%$ of Australian teachers report they are under-prepared to discuss menstruation as part of the normal curriculum [11]. This unpreparedness from teachers may explain why young women and their parents in Australia consistently report low menstrual health literacy $[7,12,13]$ and why young women often rate their period as 'normal' despite significant related absenteeism and regular non-cyclical pelvic pain symptoms [7]. This is especially concerning when combined with the low rates of seeking medical attention, as almost half of young women cannot identify the signs of secondary dysmenorrhea such as endometriosis [7]. A significant part of this issue is that menstruation is often explained only insofar as women understand enough to protect themselves from unwanted pregnancy, rather than empowering them to understand how it affects their lives [14].

Increasing health literacy through menstrual education can assist women's understanding, positively affecting their ability to engage in self-care and help identify symptoms that require further investigation $[15,16]$. In addition, there are a number of effective, non-pharmacological interventions that can reduce menstrual symptoms including heat, low intensity exercise, such as yoga or stretching, and acupressure [17-20], however most young women appear unaware of these [8]. Strategies to raise awareness of these interventions are thus required.

This pilot study aimed to determine if a three-month web-based intervention delivering menstrual education, self-screening for menstrual disturbance and evidence-based self-care, was acceptable and feasible for young women and if this intervention could increase their menstrual health literacy, improve engagement with health professionals, change their management strategies and reduce their menstrual pain.

\section{Methods}




\section{Study design:}

Ethical approval for this study was provided by the Western Sydney University Human Ethics Committee (H12599 - March 2018). All participants (and their legal guardians if aged < 18yrs) provided written informed consent prior to the start of the study. A pre-post single group design was used. The web-based resource was hosted by Western Sydney University and was developed based on the results of our national survey on menstrual health literacy [7], as well as our team's previous work on exploring effective non-pharmacological self-management strategies for dysmenorrhea and other menstrual symptoms such as Pre Menstrual Syndrome (PMS) [17-19]. The resource was co-created with an expert steering group consisting of the research team, two gynaecologists, two general practitioners (GPs), two secondary HPE teachers, a sexual and reproductive health curriculum expert, and five young women (16$25 y r s)$ from diverse backgrounds. The steering group met twice, first to discuss the content and format of the information that should be included in the resource and again approximately four weeks later, to assess the suitability of the resource content developed by the research team. Minor changes were made in response to the feedback from the steering group. The resource was developed with two main sections: Section one was evidence-based information on the menstrual cycle, covering hormonal changes during the menstrual cycle, the signs, symptoms and suspected causes of dysmenorrhea (both primary and secondary), PMS and heavy menstrual bleeding. An emphasis was placed on the range of symptoms that could be considered 'normal' and those that were likely to require further medical investigation, encouraging participants to speak to their doctor about these. The second section contained immediate self-care options including guidance on how to use heat effectively, and information on the usage of overthe-counter medications, such as ibuprofen, and a range of medium to long term self-care options including, acupressure points, a yoga sequence (Yoga Nidra) and dietary guidance. On the advice of the steering group, self-management information was delivered as a mixture of text, instructional video clips and audio recordings. Once the resource was developed, it was pilot-tested with four young women under the age of 21 , and further editorial changes were made to the content to ensure it was clear and understandable for this age group.

\section{Participants, recruitment and study flow:}

People were eligible to participate if they were currently living in Australia, aged 14-25yrs, had menstruated for at least 12 months and had regular periods (within 21 to 35 days), and had internet access on their computer, tablet or smartphone.

Participants were recruited using a variety of methods. These included paid Facebook and Instagram advertising and social media promotion by Family Planning NSW, Endometriosis Australia, ACHPER and Kimberly-Clark Australia as well as via the social media networks (both personal and professional) of the research team. Potential participants lodged their interest via a web-portal and a member of the research team (K.P.) contacted them via email. A phone call was then undertaken (if under 18 including the parents/guardians) to get consent and screen participants. 
Participants then completed baseline measures after their next menstrual period and subsequently provided with web-resource login and password. The Period ImPact and Pain Assessment (PIPPA) tool was previously developed to assist young women to determine normal from atypical period pain and interference [4, 21]. At baseline, all participants filled in an online version of the PIPPA tool, which asked five $\mathrm{Y} / \mathrm{N}$ questions regarding the impact of their menstrual symptoms. If they answered "Yes" to either four or five of the PIPPA questions, they received an email with a personalized letter advising them to make an appointment and take this letter to their doctor. The letter contained an explanation of the PIPPA tool and the related questions they had answered "Yes" to and requested that further investigations be made if the doctor felt it was appropriate. The intervention period covered three menstrual cycles. They were asked to log in to the resource at least twice in the first month to read the information section and familiarize themselves with the self-management options, and at least once per month for the next two months. Participants were encouraged to use as many or as few self-management techniques as they preferred. Regular automated reminders, either via email or SMS/text messages (based on participant preference), were sent twice per month to remind participants to use their self-management method(s) of choice. The total trial duration was four months, three months from baseline to end of intervention with a one-month follow-up period.

\section{Sample size:}

As this was a single arm pre-post pilot study, no formal sample size calculation was undertaken. Given the lack of previous data on the effectiveness of such interventions, a decision was made to include 75 participants to ensure that rare events and/or small effect sizes would be captured [22].

\section{Outcome measures and data analysis:}

Table 1 outlines the outcome measures and when these were collected. All data was captured using Castor EDC [23]. 
Table 1

Outcome measures

Measure Details Timepoints

Menstrual pain/dysmenorrhea severity
A single 0-10 numeric rating scale (NRS) for overall menstrual pain.
Baseline and at the conclusion of each of the three menstrual periods during the intervention
Analgesic usage

Type of analgesic and dosage catagorised as 'more than recommended on box', 'same as recommended on box', 'less than recommended on box'.

Baseline and at the conclusion of each of the three menstrual periods during the intervention

Self-management

Types of self-management used during the most recent menstrual period.

Baseline and at the conclusion of each of the three menstrual periods during the intervention

Internal Health Locus of Control (IHLoC)

Patient Activation Measure (PAM)
IHLoC is a measure of how much control individuals feel that they can exert over their own health was collected at baseline and end of trial[24].

PAM draws on concepts such as health locus of control, selfefficacy in managing health behaviours [and readiness to change health behaviours, but is not condition or behaviour specific. [25]. PAM scores are used to generate one of four levels, in order of increasing levels of activation; from Level 1 suggesting that the person does not yet understand their role in healthcare up to Level 4 indicating that the person is proactive and engaged in recommended health behaviours.

Health Literacy Questionnaire (HLQ)
The Health Literacy Questionnaire (HLQ) consists of 44 questions and can be either self-administered or orally administered. The HLQ identifies the specific health literacy strengths and limitations of people and communities. It examines nine areas of health literacy. Research has shown the HLQ is a robust independent measure of each of the nine identified health literacy dimensions [26].
Baseline and end of intervention.

Baseline and end of intervention. 


\begin{tabular}{|lll|}
\hline Measure & Details & Timepoints \\
\hline $\begin{array}{l}\text { Health education } \\
\text { impact } \\
\text { questionnaire } \\
\text { (HEIQ) }\end{array}$ & $\begin{array}{l}\text { The Health Education Impact Questionnaire (heiQ) is a } \\
\text { perception- and evaluation-based measure that was developed } \\
\text { to be a user-friendly, relevant and psychometrically sound } \\
\text { instrument for the comprehensive evaluation of patient } \\
\text { education programs and activities [27]. }\end{array}$ & $\begin{array}{l}\text { Baseline } \\
\text { and end of } \\
\text { intervention. }\end{array}$ \\
$\begin{array}{l}\text { Trial exit } \\
\text { questionaaire }\end{array}$ & $\begin{array}{l}\text { The trial exit questionnaire collected participant satisfaction, } \\
\text { use of self-care, changes in understanding of menstruation, } \\
\text { and information on visits to medical practitioners. }\end{array}$ & $\begin{array}{l}\text { At one- } \\
\text { month } \\
\text { follow up. }\end{array}$ \\
$\begin{array}{l}\text { Period ImPact and } \\
\text { Pain Assessment } \\
\text { Tool (PIPPA) }\end{array}$ & $\begin{array}{l}\text { A 5-item dichotomous Yes/No survey to measure pain and } \\
\text { interference related menstrual disturbance.[4, 21] }\end{array}$ & Baseline \\
\hline
\end{tabular}

Descriptive statistics, including frequencies and percentages, means and standard deviations, or median and interquartile range (IQR), were used to report recruitment and dropout rates and demographics information. All outcomes were determined a priori, and as this was a pilot study, all p-values are considered exploratory. All parametric outcomes were compared using paired t-tests, while nonparametric outcomes such as PIPPA scores were compared using the Wilcoxon signed-rank test. Missing data were dealt with via last observation carried forward (LOCF) on the assumption that those who dropped out of the trial were non-responders.

\section{Results}

Two hundred and seventy-four young women expressed interest in the trial over a three-month recruitment period. The most common reasons for trial exclusion were lack of response to screening phone calls $(n=124,45 \%)$ and being outside the age range for inclusion $(n=35,13 \%)$. Seventy-five $(27 \%)$ were eligible to participate, consented and entered the study, with $56(75 \%)$ completing the intervention. The most common reasons for drop out were lack of time $(n=9,47 \%)$ or were lost to follow-up $(n=6$, $32 \%$ ) (defined as no response after 3 weeks of attempted contact), pregnancy ( $n=2,11 \%$ ) or menstrual suppression due to contraceptive use $(n=2,11 \%)$.

Table 2 outlines the demographics and menstrual characteristics of the participants. Participants had a mean age of 20 (3.4) years, and the majority were currently at school or university (60\%). Eighteen participants $(24 \%)$ had a confirmed diagnosis of endometriosis. Almost three quarters $(73 \%)$ of the participants had previously seen a doctor for menstrual symptoms. However, only $16 \%$ were happy with the advice they received from their health professional. Eighty per cent of participants were at or had attended co-educational schools, with just over half currently attending or had attended a public school $(52 \%)$, while under a quarter $(22.5 \%)$ attended a religiously affiliated school or a private school $(17.5 \%)$. Only $40 \%$ reported they had learned about menstrual health in their Health and Physical Education (HPE) classes. 
Table 2

Demographics and Menstrual characteristics

\begin{tabular}{|c|c|}
\hline$N=75$ & Mean (SD) \\
\hline Age (y) & $20(3.4)$ \\
\hline \multirow[t]{2}{*}{ Age at menarche $(y)$} & $12(1.7)$ \\
\hline & $\mathbf{N}(\%)$ \\
\hline \multicolumn{2}{|l|}{ Occupation } \\
\hline At school or university & $45(60 \%)$ \\
\hline Working for pay & $26(34.7 \%)$ \\
\hline Other & $4(5.3 \%)$ \\
\hline \multicolumn{2}{|c|}{ Response to "I think my periods are normal" } \\
\hline Yes & $48(64 \%)$ \\
\hline No & $21(28 \%)$ \\
\hline Unsure & $6(8 \%)$ \\
\hline \multicolumn{2}{|l|}{ Regular Dysmenorrhea } \\
\hline Yes & $74(98.7 \%)$ \\
\hline No & $1(1.3 \%)$ \\
\hline \multicolumn{2}{|c|}{ Current pain management: } \\
\hline Analgesic medication & $63(84 \%)$ \\
\hline Contraceptives & $22(29.3 \%)$ \\
\hline Rest & $63(84 \%)$ \\
\hline Heat & $66(88 \%)$ \\
\hline Yoga & $9(12 \%)$ \\
\hline Acupressure & $4(5.3 \%)$ \\
\hline Pilates & 0 \\
\hline Low intensity exercise & $22(29.3 \%)$ \\
\hline Resistance exercise & $4(5.3 \%)$ \\
\hline High intensity exercise & $8(10.7 \%)$ \\
\hline
\end{tabular}




\begin{tabular}{|ll|}
\hline $\mathbf{N}=75$ & Mean (SD) \\
\hline Meditation & $12(16 \%)$ \\
\hline Herbal medicine & $14(18.7 \%)$ \\
\hline Prayer & $4(5.3 \%)$ \\
\hline Dietary changes & $11(14.7 \%)$ \\
\hline Other & $3(4 \%)$ \\
\hline Sources of information on menstruation & \\
\hline Mum & $57(76 \%)$ \\
\hline Dad & $1(1.3 \%)$ \\
\hline Female relatives & $26(34.7 \%)$ \\
\hline HPE teacher & \\
\hline Doctor & $15(20 \%)$ \\
\hline Friends & $34(45.3 \%)$ \\
\hline Social media & $32(42.7 \%)$ \\
\hline Magazines & $17(22.7 \%)$ \\
\hline Google search & $14(18.7 \%)$ \\
\hline Other & $36(48 \%)$ \\
\hline aHealth and Physical Education teacher & $7(9.3 \%)$ \\
\hline
\end{tabular}

\section{PIPPA scores and medical visits:}

Those with a diagnosis of endometriosis $(n=18)$ had a median PIPPA score of 5 , while those without $(n$ $=57)$ had a significantly lower median score of $3(p=0.037)$. Thirty-eight participants $(51 \%)$ had a PIPPA score of 4 or greater and received a referral letter for their GP. Half of those who received the referral letter subsequently made an appointment with their GP.

Just under half (32 participants, $43 \%$ ) of the study participants visited their doctor regarding their menstrual symptoms during the study period. Of those who visited their doctor, 27 participants (84\%) indicated that they made the appointment due to being involved in the intervention; either due to information they received on the website (8 participants, $30 \%$ ) or the referral letter they received (19 participants, $70 \%)$. Out of the 32 participants who visited their GP, over half (56\%) had received a referral to a gynaecologist by the end of the one month follow up period. 


\section{Menstrual management:}

Table 3 outlines the changes in specific self-management strategies that were part of the intervention between baseline and the third menstrual period. Of that $84 \%$ of participants using analgesics, the most common analgesics used prior to the study were Ibuprofen (33\%), Paracetamol (33\%) and Mefenamic acid $(18 \%)$. There were no significant changes $(p>0.05)$ in the type of analgesic used or the dosage used between baseline and the third menstrual period. Overall, use of self-management for menstrual symptoms increased from $65 \%$ of participants at baseline to $86 \%$ at the third menstrual period.

Table 3

Usage of self-management strategies over time

\begin{tabular}{|lllll|}
\hline Modality & Baseline $(\mathbf{n = 7 3 )}$ & $\begin{array}{l}\text { Cycle 1 } \\
(\mathbf{n = 6 7})\end{array}$ & $\begin{array}{l}\text { Cycle 2 } \\
(\mathbf{n = 5 9 )}\end{array}$ & $\begin{array}{l}\text { Cycle 3 } \\
(\mathbf{n}=56)\end{array}$ \\
\hline Heat & $\mathrm{N}(\%)$ & & & \\
\hline Exercise (low intensity e.g. yoga) & $22(30.1 \%)$ & $40(59.7 \%)$ & $33(55.9 \%)$ & $23(41.1 \%)$ \\
\hline Exercise (high intensity e.g. running) & $6(8.2 \%)$ & $12(17.9 \%)$ & $8(13.6 \%)$ & $11(19.6 \%)$ \\
\hline Meditation/Breathing exercises & $11(15.1 \%)$ & $20(29.9 \%)$ & $25(42.4 \%)$ & $28(50 \%)$ \\
\hline Acupressure & $1(1.4 \%)$ & $17(25.4 \%)$ & $13(22 \%)$ & $11(19.6 \%)$ \\
\hline
\end{tabular}

At the end of the one-month follow-up, $60 \%$ of participants reported that the intervention changed the way they managed their menstrual symptoms, and $85 \%$ would keep using at least one of the self-care practices they had learned.

\section{Menstrual pain and symptoms:}

Those with a diagnosis of endometriosis $(n=18)$ had a significantly $(p=0.005)$ higher menstrual pain score at baseline (7.7) compared to those without $(n=57)$ a diagnosis of endometriosis (5.6). Overall, there was a small, non-significant $(p=0.216)$ decrease in menstrual pain from $6.1(1.9)$ at baseline to 5.3 (2.2) at the end of the intervention. At one-month follow up, $4 \%$ said their menstrual symptoms were 'very much better', 1 in 5 (20\%) said their menstrual symptoms were 'much better' than before they started, almost half (46\%) said 'a little better', and just over a quarter (28.6\%) said no change.

\section{Internal Health Locus of Control}

There was a small, non-significant $(p=0.236)$ increase in mean internal Health Locus of Control from 29.19 (3.39) at baseline to 29.96 (3.25) at one-month follow up.

\section{Health literacy measures:}

Table 4 outlines the changes in PAM levels, HLQ scores and percentage of reliable change in HEIQ scores. 
Table 4

Health Literacy outcomes:

\begin{tabular}{|c|c|c|}
\hline Measure & Baseline & End of trial \\
\hline & Median (IQR) & Median (IQR) \\
\hline Patient Activation Measure (PAM) Level & $3(2-4)$ & $3(2-4)$ \\
\hline Health Literacy Questionnaire (HLQ) & Mean (SD) & Mean (SD) \\
\hline $\begin{array}{l}\text { Feeling understood and supported by } \\
\text { healthcare providers (HPS) }\end{array}$ & $3.05(0.41)$ & $3.12(0.30)$ \\
\hline $\begin{array}{l}\text { Having sufficient information to manage } \\
\text { my health (HSI) }\end{array}$ & $2.79(0.47)$ & $3.09(0.21)^{\star}$ \\
\hline Actively managing my health (AMH) & $3.01(0.38)$ & $3.05(0.35)$ \\
\hline Social support for health (SS) & $3.10(0.55)$ & $3.09(0.43)$ \\
\hline Appraisal of health information (CA) & $2.89(0.55)$ & $3.04(0.44)$ \\
\hline $\begin{array}{l}\text { Ability to actively engage with healthcare } \\
\text { providers }(A E)\end{array}$ & $3.64(0.59)$ & $3.74(0.50)$ \\
\hline Navigating the healthcare system (NHS) & $3.58(0.65)$ & $3.69(0.57)$ \\
\hline $\begin{array}{l}\text { Ability to find good health information } \\
\text { (FHI) }\end{array}$ & $3.78(0.62)$ & $3.89(0.44)$ \\
\hline $\begin{array}{l}\text { Understand health information well } \\
\text { enough to know what to do (UHI) }\end{array}$ & $4.14(0.52)$ & $4.14(0.49)$ \\
\hline $\begin{array}{l}\text { Health education impact questionnaire } \\
\text { (HEIQ) }\end{array}$ & \multicolumn{2}{|c|}{$\begin{array}{l}\text { Percentage of participants with reliable positive change } \\
\text { between baseline and end of trial }{ }^{a}\end{array}$} \\
\hline Health-directed Behaviour & \multicolumn{2}{|l|}{12.7} \\
\hline Positive \& Active Engagement in Life & \multicolumn{2}{|l|}{10.9} \\
\hline Self-monitoring and Insight & \multicolumn{2}{|l|}{14.5} \\
\hline Constructive Attitudes \& Approaches & \multicolumn{2}{|l|}{16.4} \\
\hline Skill and Technique Acquisition & \multicolumn{2}{|l|}{40.0} \\
\hline Social Integration \& Support & \multicolumn{2}{|l|}{14.5} \\
\hline Health Services Navigation & \multicolumn{2}{|l|}{20.0} \\
\hline Emotional Distress & \multicolumn{2}{|l|}{21.8} \\
\hline${ }^{*} \mathrm{p}<0.05$ (exploratory) & & \\
\hline
\end{tabular}




\section{Menstrual health literacy:}

Prior to beginning the study at baseline, only a quarter of participants $(25 \%)$ felt that they had sufficient information about their period and its symptoms, with just over half (53\%) reporting that they had some information but felt unsure about a number of aspects, with $15 \%$ being unsure if they had enough information at all. At the end of the follow-up period, $59 \%$ of participants indicated that they felt they had sufficient information about their period and its symptoms, $35 \%$ reported that they had some information but felt unsure about a number of aspects, with $6 \%$ being unsure if they had enough information at all.

At baseline, when asked about specific aspects of menstrual health, $60 \%$ indicated they knew the signs of heavy menstrual bleeding, and $69 \%$ could identify the symptoms of endometriosis. At follow-up, $87 \%$ could identify the signs of heavy menstrual bleeding, and $94 \%$ could identify the symptoms of endometriosis.

At the end of the follow-up, just under half of the participants (48.8\%) said the intervention had changed what they thought was a 'normal' period and over a third (35\%) said it corrected previous misunderstandings they had about periods and the menstrual cycle. After using the intervention, $65 \%$ said they were now 'very comfortable' talking about periods to others.

\section{Participant satisfaction:}

$85 \%$ found the web-based intervention easy to use, and $90 \%$ found the information provided 'very helpful'. A quarter of participants (25\%) were 'very satisfied' with the changes in their symptoms, and over a third (34\%) were moderately satisfied. Only one participant was unsatisfied.

\section{Discussion}

Our study found that an online intervention undertaken over three menstrual cycles could improve some key aspects of menstrual health literacy, encourage engagement with medical professionals, and provide improved understanding of both a 'normal' menstrual cycle and how to identify problematic menstrual conditions such as endometriosis and heavy menstrual bleeding.

There was an increased uptake of self-care measures over the course of the trial, especially in breathing/meditation exercises and acupressure which were low at baseline. There is some preliminary evidence that mindfulness style interventions reduce menstrual pain $[28,29]$ and there is evidence for both mindfulness and acupressure for reducing PMS symptoms [19, 30]. Exercise has the most significant reduction in pain compared to other self-care such as heat, [17] but uptake was lower than other forms of self-care. This may be due to the fact that our intervention aimed to increase health literacy, but content was not included to support behaviour change. Incorporating behaviour change theory-based content such as stepping individuals through use of behaviour change techniques [31, 32], e.g., using self-monitoring, setting goals, social support, and/or adding behaviour change support intervention methods in addition to the online platform, e.g., face-to-face methods, could further enhance 
the efficacy of the intervention in regards to changing behaviours of seeking health care and using selfmanagement strategies, such as exercise. Our team are currently working to develop such additional support, including the testing of a menstrual pain behaviour app [33]. Despite the increased uptake of these self-care measures, we did not find evidence of a clinically significant reduction in menstrual pain, however it is important to note that this study was not powered to detect any such change if it did exist. The pain score itself is also unlikely to capture the complete spectrum of bothersome menstrual symptoms such as emotional changes [6], which may explain why, despite the lack of a significant pain reduction, over half of the participants rated their menstrual symptoms as at least slightly improved.

The addition of a menstrual disturbance self-screening tool (PIPPA) to menstrual education in this study demonstrated health seeking behaviour by women to GPs and reported action by GPs to refer some participants to gynaecologists. Young women commonly report GPs being dismissive of pain and interference related menstrual disturbance $[34,35]$ and this can cause reluctance to engage with healthcare professionals [6]. In this study, the addition of a letter to GPs with PIPPA scores and explanation of relevance may well have provided a reverse education of GPs to take seriously young women's reports of menstrual disturbance. The action by GPs to refer women to gynaecologists may well have been facilitated by the combination of a high PIPPA score, providing external validation of pain and interference, and women's increased menstrual health literacy and confidence to present to GPs. Given that over half of young Australian women report symptoms of non-cyclical pelvic pain but also normalise these symptoms [3], ensuring that these young women are advised and empowered to seek medical advice is vital to ensure that the lengthy diagnostic delays are reduced [36, 37].

Certain aspects of health literacy related to agency, empowerment and improved health management skills all increased during the intervention. The significant improvement in the HSI domain of the HLQ corresponds to "Feel(ing) confident that they have all the information that they need to live with and manage their condition and to make decisions" [26]. Several domains of the HeiQ also showed reliable improvement, with the largest improvement in the skills and technique acquisition domain; improvement in this domain relates to "highly developed skills in symptom relief and techniques to manage own health" [27]. The proportion of reliable positive change in our participants was similar across most domains to previous research on the impact of chronic disease management programs in Australia between 2007-2013 [38] suggesting that, despite the online nature and minimal interaction between the research team and participants, or between participants themselves, it was similarly effective to more 'traditional' programs. Interestingly, despite these improvements there was no corresponding improvement in the internal Health Locus of Control scores over the course of the trial, but the IHLoC scores both at baseline and the end of intervention were similar to previous data on those with and without a chronic health condition [39], suggesting that these scores were already in the normal range.

These findings illustrate that a relatively large number of young people are; not receiving accurate information in schools, from parents or healthcare professionals, information is not being delivered in a suitable manner, or they are missing the information they need. Previous research in Australia has shown that when discussing a condition such as endometriosis young women wanted to know specific 
symptoms, rather than vague or general information [40]. Focussing on high schools, the HPE syllabus does not directly address menstrual health education. Content covered in the later years is linked to sexual and reproductive health through the focus area 'Relationships and Sexuality', which aims to explore resources and strategies to manage personal, physical and social changes and transitions associated with puberty as they grow older [10]. In the later years (years 9 and 10), the focus of this content shifts to sexuality and sexual health education, leaving it to the teacher's discretion to incorporate this content at all or in an effective manner beyond personal experience or from a biological lens. Given the significant number of participants attending co-educational schools $(80 \%)$, the findings of this study reveal gaps in the HPE curriculum between the menstrual health education delivered in school and what information is needed to develop young people's menstrual health literacy.

We recommend a whole-school approach to develop menstrual health literacy and strategies to support students, teachers and school staff to promote menstrual health and wellbeing. This research indicates the need for greater emphasis on menstrual health in HPE classes. Menstrual health education needs to focus on correcting mistaken assumptions about a 'normal' period or menstrual cycle, providing sufficient information about periods and their symptoms, and information about menstrual management, including self-care options and when to consult a doctor. To develop young peoples' menstrual health literacy within the critical dimension, the HPE curriculum needs to provide menstrual health education that empowers students to selectively access and critically analyse menstrual health information and to take action to promote their menstrual health [10]. Such information could potentially help to alleviate not only dysmenorrhea and related menstrual symptoms but could, by extension, increase their ability to engage fully in the classroom and extra-curricular activities. The provision of an online resource, such as the one reported in this paper, clearly offers young people and teachers additional information that they could access autonomously. Providing such a resource would ensure critical information was more broadly disseminated and independent of individual teacher capacity. Furthermore, such a tool provides young women with the knowledge to take charge of their health. Ideally, the use of such a resource would be accompanied by professional learning for teachers and potentially parents and carers of young women, to ensure that the health literacy messages received by young women are aligned.

Translational capacity of interventions is essential to consider when designing and evaluating health interventions, to ensure follow-through to sustainable policy and practice change from research settings. The Reach, Effectiveness, Adoption, Implementation, Maintenance (RE-AIM) framework [41], is one of the most commonly used implementation science frameworks. Regarding the current study, reach into the intended target population (e.g., the total number of eligible women that were exposed to the intervention invite), adoption of the intervention (e.g., the number of women out of the total potential eligible sample who joined the study) and implementation of the intervention (e.g., how the intervention was used, such as number of hours of engagement and with which elements of the online resource) were not determined. A range of social media sources were used to recruit women making it challenging to identify the total potential sample and the online platform used for intervention delivery did not capture analytics to inform use and engagement with the intervention. This study was also a short pilot study and so long-term engagement with the intervention (maintenance) was not explored. Our evaluation tools did however 
detect meaningful changes in some outcomes, suggesting that further testing is warranted to explore full scale, long-term effectiveness and implementation processes in a rigorous trial. Future work should also collect in-depth qualitative data from intervention users (e.g., women) and stakeholders (e.g., teachers) to explore how and why outcomes changed the way they did over time [42]

We have suggested that high schools may be an appropriate place to reach young women. However, consideration of other settings to promote the intervention in women and important influencers of women beyond high school should also be considered (such as through universities, pharmacies, healthcare settings, community groups and other social marketing strategies). We did not collect data on ethnicity, educational level or socio-economic status, which are associated with health disparities, potentially through health literacy[43, 44]. It may be that our resources would require tailoring to particular groups, which will need explored in future. For example, peer support (support from someone with similar characteristics to the individual and with experiential knowledge) has been shown to be particularly effective for lifestyle behaviour change in culturally diverse communities [45] and so expanding on our current intervention to add an element of peer support may be necessary to engage well with such communities.

There are several strengths to this study including the use of validated health literacy questionnaires, and the previously validated PIPPA tool to encourage engagement with health professionals. However, some important limitations must be acknowledged. Firstly, this is a pilot study and therefore was not powered to detect small, even if clinically relevant, changes between baseline to end of trial. Secondly, due to budget constraints and internal University policy, the web-based intervention had to be hosted on the universities own web platform. This platform lacks many of the features of the "modern" Web 2.0, and therefore data on which pages were interacted with and for how long, what video clips received the most views etc was not able to be retrieved. Therefore, we are unable to determine how much actual engagement with the material there was. Future versions of this content will be hosted on modern platforms that will allow the research team to use analytics to help optimise content. Finally, the outcomes of the visit to the general practitioner or gynaecologist are unknown, therefore we are unsure about how many of the participants, if any, received a further diagnosis such as endometriosis for their symptoms.

\section{Conclusion}

A web based intervention, with minimal setup and ongoing costs, can provide clinically relevant improvements in health literacy, remedy previous misconceptions about menstruation and increase awareness and up-take of evidence based self-care methods. The used PIPPA tool was a simple but effective means of empowering and encouraging visits to health professionals. Future research should explore the most acceptable way to deliver this information, and to ensure that not only young people, but their teachers and parents/guardians also have access to accurate, evidence based information on menstruation and it's management. 


\section{Declarations}

Competing interests: The authors declare the following competing interests: As a medical research institute, NICM Health Research Institute receives research grants and donations from foundations, universities, government agencies and industry. Sponsors and donors provide untied and tied funding for work to advance the vision and mission of the Institute. This study was funded by a partnership grant between Kimberly-Clark Australia and Western Sydney University. Kimberly-Clark helped inform the study design but had no role in the collection, analysis/interpretation of data or writing of the study report. There are no restrictions on publication imposed.

Funding for this study was provided as part of a WSU partnership grant between Western Sydney University and Kimberly-Clark Australia. Thank you to all those organisations who promoted this on their social media including Family Planning NSW, Endometriosis Australia, ACHPER and Kimberly-Clark Australia.

\section{References}

1. Armour M, Parry K, Manohar N, Holmes K, Ferfolja T, Curry C, et al. The Prevalence and Academic Impact of Dysmenorrhea in 21,573 Young Women: A Systematic Review and Meta-Analysis. J Womens Health (Larchmt). 2019;28(8):1161-71. Epub 2019/06/07. doi: 10.1089/jwh.2018.7615. PubMed PMID: 31170024.

2. Friberg $B$, Orno $A K$, Lindgren $A$, Lethagen $S$. Bleeding disorders among young women: a populationbased prevalence study. Acta Obstet Gynecol Scand. 2006;85(2):200-6. Epub 2006/03/15. doi: 10.1080/00016340500342912. PubMed PMID: 16532915.

3. Armour M, Ferfolja T, Curry C, Hyman MS, Parry K, Chalmers KJ, et al. The Prevalence and Educational Impact of Pelvic and Menstrual Pain in Australia: A National Online Survey of 4202 Young Women Aged 13-25 Years. J Pediatr Adolesc Gynecol. 2020;33(5):511-8. Epub 2020/06/17. doi: 10.1016/j.jpag.2020.06.007. PubMed PMID: 32544516.

4. Parker MA, Sneddon AE, Arbon P. The menstrual disorder of teenagers (MDOT) study: determining typical menstrual patterns and menstrual disturbance in a large population-based study of Australian teenagers. BJOG. 2010;117(2):185 - 92. Epub 2009/10/31. doi: 10.1111/j.14710528.2009.02407.x. PubMed PMID: 19874294.

5. Hillen TI, Grbavac SL, Johnston PJ, Straton JA, Keogh JM. Primary dysmenorrhea in young Western Australian women: prevalence, impact, and knowledge of treatment. The Journal of adolescent health: official publication of the Society for Adolescent Medicine. 1999;25(1):40-5. Epub 1999/07/27. PubMed PMID: 10418884.

6. Armour M, Dahlen HG, Smith CA. More Than Needles: The Importance of Explanations and Self-Care Advice in Treating Primary Dysmenorrhea with Acupuncture. Evid Based Complement Alternat Med. 2016;2016:3467067. Epub 2016/06/01. doi: 10.1155/2016/3467067. PubMed PMID: 27242909; PubMed Central PMCID: PMCPMC4875987. 
7. Armour M, Hyman MS, Al-Dabbas M, Parry K, Ferfolja T, Curry C, et al. Menstrual Health Literacy and Management Strategies in Young Women in Australia: A National Online Survey of Young Women Aged 13-25 Years. J Pediatr Adolesc Gynecol. 2021;34(2):135-43. Epub 2020/11/15. doi: 10.1016/j.jpag.2020.11.007. PubMed PMID: 33188935.

8. Armour M, Parry K, Al-Dabbas MA, Curry C, Holmes K, MacMillan F, et al. Self-care strategies and sources of knowledge on menstruation in 12,526 young women with dysmenorrhea: A systematic review and meta-analysis. PLoS One. 2019;14(7):e0220103. Epub 2019/07/25. doi: 10.1371/journal.pone.0220103. PubMed PMID: 31339951; PubMed Central PMCID: PMCPMC6655766.

9. Nielsen-Bohlman L. Health Literacy: A Prescription to End Confusion. In: Nielsen-Bohlman L, Panzer AM, Kindig DA, editors. Health Literacy: A Prescription to End Confusion. Washington (DC)2004.

10. Australian Curriculum Assessment and Reporting Authority [ACARA]. Foundation to year 10 curriculum: Health and Physical Education 2014. Available from: https://www.australiancurriculum.edu.au/f-10-curriculum/health-and-physical-education/

11. Duffy B, Fotinatos N, Smith A, Burke J. Puberty, health and sexual education in Australian regional primary schools: Year 5 and 6 teacher perceptions. Sex Education. 2013;13(2):186-203. doi: 10.1080/14681811.2012.678324.

12. Bellis EK, Li AD, Jayasinghe YL, Girling JE, Grover SR, Peate M, et al. Exploring the Unmet Needs of Parents of Adolescent Girls with Heavy Menstrual Bleeding and Dysmenorrhea: A Qualitative Study. J Pediatr Adolesc Gynecol. 2020;33(3):271-7. Epub 2019/12/25. doi: 10.1016/j.jpag.2019.12.007. PubMed PMID: 31874316.

13. Li AD, Bellis EK, Girling JE, Jayasinghe YL, Grover SR, Marino JL, et al. Unmet Needs and Experiences of Adolescent Girls with Heavy Menstrual Bleeding and Dysmenorrhea: A Qualitative Study. J Pediatr Adolesc Gynecol. 2020;33(3):278-84. Epub 2019/11/26. doi: 10.1016/j.jpag.2019.11.007. PubMed PMID: 31765795.

14. Diorio JA, Munro JA. Doing Harm in the Name of Protection: Menstruation as a topic for sex education. Gender and Education. 2000;12(3):347-65. doi: 10.1080/713668302.

15. Wong CL, Ip WY, Choi KC, Lam LW. Examining self-care behaviors and their associated factors among adolescent girls with dysmenorrhea: An application of Orem's self-care deficit nursing theory. Journal of Nursing Scholarship. 2015;47(3):219-27. doi: 10.1111/jnu.12134. PubMed PMID: 201519156-005.

16. Bush D, Brick E, East MC, Johnson N. Endometriosis education in schools: A New Zealand model examining the impact of an education program in schools on early recognition of symptoms suggesting endometriosis. Aust N Z J Obstet Gynaecol. 2017;57(4):452-7. Epub 2017/03/30. doi: 10.1111/ajo.12614. PubMed PMID: 28349513.

17. Armour M, Smith CA, Steel KA, Macmillan F. The effectiveness of self-care and lifestyle interventions in primary dysmenorrhea: a systematic review and meta-analysis. BMC Complement Altern Med. 
2019;19(1):22. Epub 2019/01/19. doi: 10.1186/s12906-019-2433-8. PubMed PMID: 30654775; PubMed Central PMCID: PMCPMC6337810.

18. Armour M, Ee CC, Naidoo D, Ayati Z, Chalmers KJ, Steel KA, et al. Exercise for dysmenorrhoea. The Cochrane database of systematic reviews. 2019;9:CD004142. Epub 2019/09/21. doi: 10.1002/14651858.CD004142.pub4. PubMed PMID: 31538328.

19. Armour M, Ee CC, Hao J, Wilson TM, Yao SS, Smith CA. Acupuncture and acupressure for premenstrual syndrome. The Cochrane database of systematic reviews. 2018;8:CD005290. Epub 2018/08/15. doi: 10.1002/14651858.CD005290.pub2. PubMed PMID: 30105749.

20. Matthewman G, Lee A, Kaur JG, Daley AJ. Physical activity for primary dysmenorrhea: a systematic review and meta-analysis of randomized controlled trials. Am J Obstet Gynecol. 2018;219(3):255 e1e20. Epub 2018/04/10. doi: 10.1016/j.ajog.2018.04.001. PubMed PMID: 29630882.

21. Parker MA, Kent AL, Sneddon A, Wang J, Shadbolt B. The menstrual disorder of teenagers (MDOT) study No 2: Period ImPact and Pain Assessment (PIPPA) tool validation in a large population based cross-sectional study of Australian teenagers. J Pediatr Adolesc Gynecol. 2021. Epub 2021/06/26. doi: 10.1016/j.jpag.2021.06.003. PubMed PMID: 34171477.

22. Bell ML, Whitehead AL, Julious SA. Guidance for using pilot studies to inform the design of intervention trials with continuous outcomes. Clin Epidemiol. 2018;10:153-7. Epub 2018/02/07. doi: 10.2147/CLEP.S146397. PubMed PMID: 29403314; PubMed Central PMCID: PMCPMC5779280.

23. Castor EDC. Castor Electronic Data Capture 2019 [August 28, 2019]. Available from: https://castoredc.com.

24. Wallston KA, Wallston BS, DeVellis R. Development of the Multidimensional Health Locus of Control (MHLC) Scales. Health Educ Monogr. 1978;6(2):160-70. Epub 1978/01/01. doi:

10.1177/109019817800600107. PubMed PMID: 689890.

25. Hibbard JH, Stockard J, Mahoney ER, Tusler M. Development of the Patient Activation Measure (PAM): conceptualizing and measuring activation in patients and consumers. Health services research. 2004;39(4p1):1005-26.

26. Osborne RH, Batterham RW, Elsworth GR, Hawkins M, Buchbinder R. The grounded psychometric development and initial validation of the Health Literacy Questionnaire (HLQ). BMC Public Health. 2013;13(1):658. doi: 10.1186/1471-2458-13-658.

27. Osborne RH, Elsworth GR, Whitfield K. The Health Education Impact Questionnaire (heiQ): An outcomes and evaluation measure for patient education and self-management interventions for people with chronic conditions. Patient Education and Counseling. 2007;66(2):192-201. doi: https://doi.org/10.1016/j.pec.2006.12.002.

28. Payne LA, Seidman LC, Romero T, Sim M-S. An Open Trial of a Mind-Body Intervention for Young Women with Moderate to Severe Primary Dysmenorrhea. Pain Medicine. 2020;21(7):1385-92. doi: 10.1093/pm/pnz378.

29. Purnamasari KD, Rohita T, Zen DN, Ningrum WM. The Effect of Deep Breathing Exercise on Menstrual Pain Perception in Adolescents with Primary Dysmenorrhea. Pertanika Journal. 
2020;2(28):649-57.

30. Panahi F, Faramarzi M. The effects of mindfulness-based cognitive therapy on depression and anxiety in women with premenstrual syndrome. Depression research and treatment. 2016;2016.

31. Michie S, van Stralen MM, West R. The behaviour change wheel: a new method for characterising and designing behaviour change interventions. Implement Sci. 2011;6:42. Epub 2011/04/26. doi: 10.1186/1748-5908-6-42. PubMed PMID: 21513547; PubMed Central PMCID: PMCPMC3096582.

32. Michie S, Richardson M, Johnston M, Abraham C, Francis J, Hardeman W, et al. The behavior change technique taxonomy ( $v 1)$ of 93 hierarchically clustered techniques: building an international consensus for the reporting of behavior change interventions. Ann Behav Med. 2013;46(1):81-95. Epub 2013/03/21. doi: 10.1007/s12160-013-9486-6. PubMed PMID: 23512568.

33. Wang J, Rogge AA, Armour M, Smith CA, D'Adamo CR, Pischke CR, et al. International ResearchKit App for Women with Menstrual Pain (Development, Access, and Engagement): Pragmatic Randomized Control Trial. JMIR Mhealth Uhealth. 2020;8(2):e14661. Epub 9.2.2020. doi: 10.2196/14661. PubMed PMID: 32044758.

34. Young K, Fisher J, Kirkman M. Endometriosis and fertility: women's accounts of healthcare. Human Reproduction. 2016;31(3):554-62. doi: 10.1093/humrep/dev337.

35. Moradi M, Parker M, Sneddon A, Lopez V, Ellwood D. Impact of endometriosis on women's lives: a qualitative study. BMC women's health. 2014;14(1):123. Epub 2014/10/05. doi: 10.1186/1472-687414-123. PubMed PMID: 25280500; PubMed Central PMCID: PMCPMC4287196.

36. Armour M, Sinclair J, Ng CHM, Hyman MS, Lawson K, Smith CA, et al. Endometriosis and chronic pelvic pain have similar impact on women, but time to diagnosis is decreasing: an Australian survey. Sci Rep. 2020;10(1):16253. Epub 2020/10/03. doi: 10.1038/s41598-020-73389-2. PubMed PMID: 33004965; PubMed Central PMCID: PMCPMC7529759.

37. O'Hara R, Rowe H, Fisher J. Managing endometriosis: a cross-sectional survey of women in Australia. J Psychosom Obstet Gynaecol. 2020:1-8. Epub 2020/10/15. doi: 10.1080/0167482X.2020.1825374. PubMed PMID: 33050751.

38. Elsworth GR, Osborne RH. Percentile ranks and benchmark estimates of change for the Health Education Impact Questionnaire: Normative data from an Australian sample. SAGE Open Med. 2017;5:2050312117695716. Epub 2017/06/01. doi: 10.1177/2050312117695716. PubMed PMID: 28560039; PubMed Central PMCID: PMCPMC5435365.

39. Schützler L, Witt CM. Internal health locus of control in users of complementary and alternative medicine: a cross-sectional survey. BMC Complementary and Alternative Medicine. 2014;14(1):320. doi: 10.1186/1472-6882-14-320.

40. Shadbolt NA, Parker MA, Orthia LA. Communicating endometriosis with young women to decrease diagnosis time. Health Promotion Journal of Australia. 2013;24(2):151-4. doi: https://doi.org/10.1071/HE12915.

41. Glasgow RE, Vogt TM, Boles SM. Evaluating the public health impact of health promotion interventions: the RE-AIM framework. Am J Public Health. 1999;89(9):1322-7. Epub 1999/09/04. 
doi: 10.2105/ajph.89.9.1322. PubMed PMID: 10474547; PubMed Central PMCID: PMCPMC1508772.

42. Glasgow RE, Harden SM, Gaglio B, Rabin B, Smith ML, Porter GC, et al. RE-AIM Planning and Evaluation Framework: Adapting to New Science and Practice With a 20-Year Review. Front Public Health. 2019;7:64. Epub 2019/04/16. doi: 10.3389/fpubh.2019.00064. PubMed PMID: 30984733; PubMed Central PMCID: PMCPMC6450067.

43. Rikard RV, Thompson MS, McKinney J, Beauchamp A. Examining health literacy disparities in the United States: a third look at the National Assessment of Adult Literacy (NAAL). BMC Public Health. 2016;16:975. Epub 2016/09/15. doi: 10.1186/s12889-016-3621-9. PubMed PMID: 27624540; PubMed Central PMCID: PMCPMC5022195.

44. Stormacq C, Van den Broucke S, Wosinski J. Does health literacy mediate the relationship between socioeconomic status and health disparities? Integrative review. Health Promot Int. 2019;34(5):e1e17. Epub 2018/08/15. doi: 10.1093/heapro/day062. PubMed PMID: 30107564.

45. Fisher EB, Boothroyd RI, Coufal MM, Baumann LC, Mbanya JC, Rotheram-Borus MJ, et al. Peer support for self-management of diabetes improved outcomes in international settings. Health Aff (Millwood). 2012;31(1):130-9. doi: 10.1377/hlthaff.2011.0914. PubMed PMID: 22232103. 